\title{
Early experience with COVID-19 patients in a private tertiary hospital in the Philippines: Implications on surge capacity, healthcare systems response, and clinical care
}

\author{
Cybele L. Abad ${ }^{\mathrm{a}, *}$, Mary Ann D. Lansang ${ }^{\mathrm{a}, \mathrm{b}}$, Cynthia P. Cordero ${ }^{\mathrm{b}}$, Ethel Dominique E. Viray ${ }^{\mathrm{a}}$, \\ Beatrice J. Tiangco ${ }^{c}$, Jia An G. Bello ${ }^{a}$, Jan Jorge M. Francisco ${ }^{a}$, Marja B. Buensalido ${ }^{a}$, \\ Maria Fe R. Tayzon ${ }^{\text {, }}$ Karl Evans R. Henson ${ }^{a}$, Regina P. Berba ${ }^{a}$, Elizabeth Paz- Pacheco ${ }^{\text {d, }}$ \\ Mediadora C. Saniel ${ }^{\mathrm{a}}$
}

${ }^{a}$ Department of Medicine, Section of Infectious Diseases, The Medical City, Pasig City, Philippines

${ }^{\mathrm{b}}$ Department of Clinical Epidemiology, College of Medicine, University of the Philippines-Manila, Philippines

${ }^{\mathrm{c}}$ Department of Medicine, Section of Oncology, The Medical City, Pasig City, Philippines

d Department of Medicine, Section of Endocrinology, The Medical City, Pasig City, Philippines

\section{A R T I C L E I N F O}

\section{Keywords:}

COVID-19

Surge capacity

Healthcare response

Clinical profile

Outcome

\begin{abstract}
A B S T R A C T
Background: Our healthcare institution was one of the first to see SARS CoV-2 cases in the country. We describe the early COVID-19 experience of a private hospital in the Philippines and discuss the healthcare system response in the setting of surge capacity.

Methods: We reviewed the medical records of adult COVID-19 hospitalized patients admitted in March 2020. We reported their demographic and clinical characteristics using descriptive statistics.

Results: Of 40 patients admitted, $23(57.5 \%)$ were male and $19(47.5 \%)$ were aged $<60$ years. Most ( $n=27$, 67.5\%) had moderate-risk, 9 (22.5\%) had high-risk, and 4 (10\%) had low-risk COVID-19. SARS-CoV-2 testing took 5.5 (range 1-10) days. Overall mortality rate was 6/40 (15.0\%). Clinical cure was documented in all lowrisk patients, 25 (92.6\%) moderate-risk patients, and only $1(11.1 \%)$ high-risk patient. In response to the surge, the hospital rapidly introduced one-way traffic systems, dedicated screening, triage and Emergency Department areas for COVID-19, a clinical pathway, engineering controls, patient cohorting, and strict infection prevention and control measures.

Conclusion: Majority of patients recovered from COVID-19. Older age and high-risk pneumonia were associated with poor outcomes. Adaptations to hospital structure and staff were quickly made in response to surge capacity, although our response was hampered by prolonged time to COVID-19 confirmation. Our study underscores the urgent need for rapid adaptive response by the healthcare system to address the surge of cases.
\end{abstract}

\section{Introduction}

The novel coronavirus, SARS COV-2, first isolated in Hubei, China in December 2019, has caused a global pandemic. ${ }^{1}$ As of October 8, 2020 there were $36,002,827$ cases worldwide, with 1,049,810 reported deaths by the World Health Organization (WHO) daily tracker. Case series from China have been published, describing the epidemiology and early outcomes of COVID-19. ${ }^{2-4}$ The first case of COVID-19 in the Philippines was confirmed on January $27,2020^{5}$ and local transmission was reported on March 7, 2020. ${ }^{6}$

The Medical City (TMC) was one of the first private hospitals in the Philippines to report a confirmed COVID-19 case. To date, published data regarding healthcare system response in the Asia-Pacific region remain limited, with few published case series on COVID-19 in the

\footnotetext{
* Corresponding author.

E-mail addresses: cybelemd@yahoo.com, crabad@up.edu.ph (C.L. Abad), mlansang@gmail.com (M.A.D. Lansang), cpcordero@up.edu.ph (C.P. Cordero),

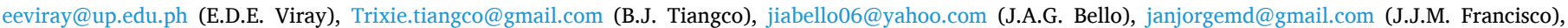

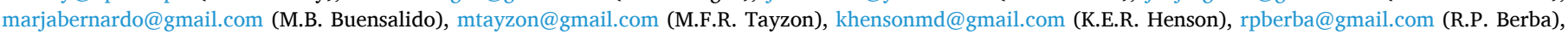
eppacheco@gmail.com (E.P. Pacheco),drsaniel@gmail.com (M.C. Saniel).
} 
Philippines, and none in the private health care setting. We aimed to: (1) describe the clinical characteristics, hospital course, and outcomes of the first 40 hospitalized Filipino patients diagnosed with COVID-19; and (2) describe healthcare system measures undertaken to respond rapidly to the COVID-19 surge.

\section{Methods}

\subsection{Patient selection}

We reviewed the medical records of all hospitalized, confirmed COVID-19 patients $\geq 18$ years old at TMC, Pasig City, Philippines from March 5, 2020-March 28, 2020. We excluded the following: patients $<18$ years old, patients with suspected or probable COVID-19 not confirmed by RT-PCR, and those admitted for $<24 \mathrm{~h}$. The TMC institutional review board (IRB) approved this retrospective study (IRB \# GCSMed-2020-030) including waiver of patient informed consent. Through chart review, study authors (CLA, EDV, BT, JB, JF) obtained demographic data, information on exposure or travel, clinical symptoms at presentation, relevant physical examination findings, and laboratory and radiologic results on pre-determined days (Day 0, 3, 5 7, 10, 14, 21, and 28). All laboratory tests, radiologic assessments and treatments were performed at the discretion of the healthcare team. For those patients still admitted, patient data were censored at the time of data cutoff, on April 12, 2020. The study authors (CLA, EDV) created a database using the Research Electronic Data Capture software (REDCap, Vanderbilt University) (https://redcapinfo.ucdenver.edu/citing-redcap. html).

\subsection{Definitions}

For this study, the following definitions were used: ARI - persons with acute respiratory infection ${ }^{7}$; Probable COVID-19 - symptomatic individuals suspected to have COVID- $19^{8}$; Confirmed COVID-19 - any individual with a positive RNA RT-PCR test for SARS CoV-2; Low-risk COVID-19 - any individual confirmed to have COVID-19 and fulfilling criteria for community-acquired pneumonia low-risk (CAP-LR) as stated in the interim Philippine Society for Microbiology and Infectious Diseases (PSMID) guidelines ${ }^{9}$; Moderate-risk COVID-19 - any individual confirmed to have COVID-19 and fulfilling criteria for community-acquired pneumonia moderate-risk (CAP-MR) as stated in the interim PSMID guidelines ${ }^{9}$; High-risk or severe COVID-19 - any individual confirmed to have COVID-19 and fulfilling criteria for CAP-high risk as stated in the interim PSMID guidelines, ${ }^{9}$ or admitted in the ICU. We used standard definitions from the United States (US) Centers for Disease Control (CDC) for hospital-acquired infections including hospital acquired pneumonia (HAP), ventilator-associated pneumonia (VAP), and catheter-related bloodstream infections (CRBSI). ${ }^{10}$ Acute respiratory distress syndrome (ARDS) was defined using the Berlin Definition. ${ }^{11}$ We defined patient outcomes as follows: Clinical cure composite of clinical improvement (e.g., no fever for 24 hours, decreasing oxygen requirement, improvement in cough/well being, improvement in imaging, decline in inflammatory parameters); virologic cure - repeat swab for SARS CoV-2 negative at least once at the time of discharge.

\subsection{Specimen collection and testing}

Clinical specimens for COVID-19 diagnostic testing were obtained in accordance with the PSMID guidelines. All clinical specimens were tested using Sansure Biotech diagnostic kits (PCR-Fluorescent Probe). The kit is an RNA-based one-tube technology mobile platform equipped with an automatic nucleic acid extractor, shortening detection time and allowing recognition of suspected cases. ${ }^{12}$ All RT-PCR tests were run by the Research Institute for Tropical Medicine (RITM), Philippines.

\subsection{Data analysis}

For this case series, we used descriptive statistics and determined frequency distributions of demographic and clinical characteristics for quantitative variables. We used median as our measure of central tendency in a small patient population with small and large values. For measures of dispersion, we provided the range of the quantitative variables, and added information on the interquartile range (IQR), particularly for skewed distributions and variables with outliers.

\section{Results}

\subsection{Characteristics of the study cohort}

Of the first 40 confirmed cases of COVID-19, 23 (57.5\%) were male, with a median age of 60.5 (range 22-86) years. Most $(n=27,67.5 \%)$ were diagnosed to have moderate-risk COVID-19; 9 (22.5\%) had highrisk; and $4(10 \%)$ had low-risk COVID-19. Among those $\geq 60$ years (n $=21), 15$ (71.4\%) had moderate-risk COVID-19; 6 (28.6\%) had high risk COVID-19; and none were low-risk (Table 1). Majority of patients ( $\mathrm{n}=$ $27,67.5 \%$ ) had at least one co-morbid illness, the most common being cardiovascular disease (CVD) $(\mathrm{n}=23,85.2 \%$ and diabetes mellitus (DM) ( $\mathrm{n}=14,51.9 \%$ ).

We also noted a cluster of cases within a family with possible secondary transmission to a health care worker (HCW) (Supplementary Appendix A Fig. A.1). Only five patients (12.5\%) had a history of international travel within 14 days of symptom onset - two arrived from the US and one each from Thailand, Saudi Arabia, and the United Kingdom.

\subsection{Signs and symptoms}

Nineteen patients (47.5\%) consulted in the ambulatory setting or at another hospital prior to hospitalization; median time from symptom onset to date of first ambulatory consult was 4 days (IQR $=5$ ).

Majority ( $\mathrm{n}=39,97.5 \%$ ) of patients had symptoms. Median time from onset of first symptom to date of admission was 7 (range 0-42) days. The most common symptoms were: cough $(n=33,84.6 \%)$ and fever $(n=28,74.3 \%)$, followed by dyspnea $(n=15,38.5 \%)$ and generalized weakness $(n=15,38.5 \%)$ (Table 1$)$. Among patients with details on the nature of their cough $(n=29)$, it was described as dry ( $n=$ $14)$, productive $(n=15)$, or intermittent $(n=7)$. Dyspnea was described only in a few patients $(n=7)$, characterized as occurring at rest $(n=3)$ or progressive ( $n=7$ ), while no further details on the symptom of weakness were available. The temperature was $<38^{\circ} \mathrm{C}$ among 24 (60\%) patients, with overall median temperature of $37.8^{\circ} \mathrm{C}$ (range $36.0-39.7^{\circ} \mathrm{C}$ ). Fever occurred in 19 patients during hospital admission, with a range of $37.8-39.7^{\circ} \mathrm{C}$ and median duration of 3 (range: $1-29$ ) days. Median time to confirmation of COVID-19 diagnosis by RT-PCR was 5.5 (range 1-10) days.

\subsection{Diagnostic findings}

On admission, 37 (92.5\%) had a baseline complete blood count. Median (min-max) white blood cell count and absolute lymphocyte count were $5.8 \times 10^{9}$ cells $/ \mathrm{L}(3.6-22.4)$, and $>1 \times 10^{9}$ cells $/ \mathrm{L}$, respectively. Viral film array $(6 / 40)$ and rapid influenza tests $(3 / 40)$ were negative. Admission chest radiographs were obtained in 38 patients (95\%), showing bilateral interstitial infiltrates in 18 (47.3\%), normal radiographic findings in $10(26.3 \%)$ and unilateral infiltrates in 5 (13.1\%) patients. Only 12 patients had high-resolution computed tomographic (CT) scan of the chest with majority $(11 / 12,91.67 \%)$ showing bilateral findings (Table 1 ). 
Table 1

Demographic, clinical, and laboratory profile of the COVID-19 Patients according to Severity of Illness.

\begin{tabular}{|c|c|c|c|c|}
\hline CHARACTERISTIC & $\begin{array}{l}\text { ALL CASES } \\
(\mathrm{N}=40)<\end{array}$ & $\begin{array}{l}\text { Low Risk } \\
(\mathrm{n}=4)\end{array}$ & $\begin{array}{l}\text { Moderate } \\
\text { Risk } \\
(\mathrm{n}=27)\end{array}$ & $\begin{array}{l}\text { High Risk } \\
(\mathrm{n}=9)\end{array}$ \\
\hline \multicolumn{5}{|l|}{ DEMOGRAPHICS } \\
\hline $\begin{array}{l}\text { Median (IQR) } \\
\min -\max \end{array}$ & $\begin{array}{l}60.5(26) \\
22-86\end{array}$ & $\begin{array}{l}34.5(19) \\
22-45\end{array}$ & $\begin{array}{l}62.0(28) \\
25-77\end{array}$ & $\begin{array}{l}65.2(22) \\
47-86\end{array}$ \\
\hline $\begin{array}{l}\text { Age, } \geq 60 \text { years, No. } \\
\text { (\%) }\end{array}$ & $21(52.5)$ & 0 & $15(55.6)$ & $6(66.7)$ \\
\hline Sex, Male, No. (\%) & $23(57.5)$ & 0 & $19(70.4)$ & $4(44.4)$ \\
\hline $\begin{array}{l}\text { History of consult as } \\
\text { outpatient prior to } \\
\text { admission, No. (\%) }\end{array}$ & $19(47.5)$ & 0 & $14(51.8)$ & $5(55.6)$ \\
\hline \multicolumn{5}{|l|}{$\begin{array}{l}\text { Days between onset of } \\
\text { symptoms and } \\
\text { consult, }\end{array}$} \\
\hline $\begin{array}{l}\text { Median (IQR) } \\
\min -\max \end{array}$ & $\begin{array}{l}4(5) \\
0-9\end{array}$ & - & $\begin{array}{l}3(3) \\
1-7\end{array}$ & $\begin{array}{l}6(2) \\
0-9\end{array}$ \\
\hline $\begin{array}{l}\text { Days between onset of } \\
\text { symptoms and } \\
\text { admission, } \\
\text { Median (IQR) } \\
\text { min-max }\end{array}$ & $\begin{array}{l}\mathrm{n}=39 \\
7(4) \\
0-42\end{array}$ & $\begin{array}{l}\mathrm{n}=3 \\
8(12) \\
4-16\end{array}$ & $\begin{array}{l}\mathrm{n}=27 \\
7(4) \\
0-42\end{array}$ & $\begin{array}{l}n=9 \\
6(3) \\
2-14\end{array}$ \\
\hline \multicolumn{5}{|l|}{$\begin{array}{l}\text { Turn-around time, } \\
\text { days }\end{array}$} \\
\hline $\begin{array}{l}\text { Median (IQR) } \\
\text { min-max }\end{array}$ & $\begin{array}{l}5.5(4) \\
1-10\end{array}$ & $\begin{array}{l}3(4) \\
2-10\end{array}$ & $\begin{array}{l}6(5) \\
1-9\end{array}$ & $\begin{array}{l}5(4) \\
2-9\end{array}$ \\
\hline \multicolumn{2}{|c|}{ COMPLETE BLOOD COUNT $(\mathrm{n}=37)$} & & $\mathbf{n}=\mathbf{9}$ \\
\hline $\begin{array}{l}\text { Median (IQR) } \\
\min -\max \end{array}$ & $\begin{array}{l}133(24) \\
108-184\end{array}$ & $\begin{array}{l}136(3) \\
133-139\end{array}$ & $\begin{array}{l}139(30.5) \\
108-184\end{array}$ & $\begin{array}{l}126(9) \\
115-140\end{array}$ \\
\hline $\begin{array}{l}\text { Hematocrit } \\
\quad \text { Median (IQR) } \\
\text { min-max }\end{array}$ & $\begin{array}{l}0.40 \\
(0.08) \\
0.31-0.56\end{array}$ & $\begin{array}{l}0.41 \\
(0.06) \\
0.31-0.42\end{array}$ & $\begin{array}{l}0.42 \\
(0.07) \\
0.31-0.56\end{array}$ & $\begin{array}{l}0.38 \\
(0.03) \\
0.35-0.41\end{array}$ \\
\hline $\begin{array}{l}\text { WBC }\left(\times 10^{9} / \mathrm{L}\right) \\
\text { Median (IQR) } \\
\text { min-max }\end{array}$ & $\begin{array}{l}5.8 \\
(4.6) \\
3.6-22.4\end{array}$ & $\begin{array}{l}5.9 \\
(5.47) \\
5.19-16.04\end{array}$ & $\begin{array}{l}5.6 \\
(4.48) \\
3.6-17.79\end{array}$ & $\begin{array}{l}7.1 \\
(7.4) \\
4.1-22.4\end{array}$ \\
\hline \multicolumn{5}{|c|}{ Platelets $\left(\times 10^{9} / \mathrm{L}\right)$ categories, No. (\%) } \\
\hline $100-150$ & $2 / 37(5.4)$ & 0 & 0 & $2(22.2)$ \\
\hline$>150$ & $\begin{array}{l}35 / 37 \\
(94.6)\end{array}$ & $4(100)$ & $24(100)$ & $7(77.8)$ \\
\hline \multicolumn{5}{|c|}{ Cytopenia categories, No. (\%) } \\
\hline None & $\begin{array}{l}35 / 37 \\
(94.6)\end{array}$ & $4(100)$ & $23(95.8)$ & $8(88.9)$ \\
\hline One-lineage & $2 / 37(5.4)$ & 0 & $1(4.2)$ & $1(11.1)$ \\
\hline $\begin{array}{l}\text { Creatinine (mg/dL) cat } \\
(\%)\end{array}$ & gories, No. & $\mathrm{n}=4$ & $\mathrm{n}=\mathbf{2 2}$ & $\mathbf{n}=\mathbf{9}$ \\
\hline$<1$ & $\begin{array}{l}25 / 35 \\
(71.4)\end{array}$ & $4(100.0)$ & $16(72.7)$ & $5(55.6)$ \\
\hline $1-2$ & $\begin{array}{l}8 / 35 \\
(22.9)\end{array}$ & 0 & $5(22.7)$ & $3(33.3)$ \\
\hline$>2$ & $2 / 35(5.7)$ & 0 & $1(4.5 \%)$ & $1(11.1)$ \\
\hline \multicolumn{5}{|c|}{ ALT (IU/L) categories, No. (\%) } \\
\hline Normal (0-50) & $\begin{array}{l}12 / 18 \\
(66.7)\end{array}$ & $1(100)$ & $10(83.3)$ & $1(20.0)$ \\
\hline $\begin{array}{l}1-2 x \text { elevated }(>50 \text { to } \\
100)\end{array}$ & $\begin{array}{l}5 / 18 \\
(27.8)\end{array}$ & 0 & $1(8.3)$ & $4(80.0)$ \\
\hline $\begin{array}{l}2-3 x \text { elevated }(>100 \text { to } \\
<150)\end{array}$ & $1 / 18(5.6)$ & 0 & $1(8.3)$ & 0 \\
\hline$>3 x$ elevated $(\geq 150)$ & 0 & - & - & - \\
\hline \multicolumn{5}{|l|}{ IMAGING } \\
\hline Bilateral infiltrate & $18(45.0)$ & 0 & $12(44.4)$ & $6(66.7)$ \\
\hline Unilateral & $5(12.5)$ & 0 & $3(11.1)$ & $2(22.2)$ \\
\hline Normal & $10(25.0)$ & $3(75.0)$ & $6(22.2)$ & $1(11.1)$ \\
\hline Other Findings & $5(12.5)$ & $1(25.0)$ & $4(14.8)$ & 0 \\
\hline Not Done & $2(5.0)$ & 0 & $2(7.4)$ & 0 \\
\hline \multicolumn{5}{|l|}{$\begin{array}{l}\text { Chest CT Scan, No. } \\
\text { (\%) }\end{array}$} \\
\hline Unilateral & $1(2.5)$ & $1(25.0)$ & 0 & 0 \\
\hline Bilateral infiltrate & $11(27.5)$ & 0 & $10(37.0)$ & $1(11.1)$ \\
\hline Not done & $28(70.0)$ & $3(75.0)$ & $17(63.0)$ & $8(88.9)$ \\
\hline
\end{tabular}

ALT - alanine aminotransferase, AST - aspartate aminotransferase, IQR interquartile range, NI - not indicated, TMC - The Medical City.

\subsection{Drugs used for treatment}

\subsubsection{Medications for COVID-19}

After routine consent was obtained, at least one investigational drug for COVID-19 was administered ( $\mathrm{n}=29,72.5 \%)$. Chloroquine (CQ) ( $=18)$ or hydroxychloroquine (HCQ) $(n=9)$ was given most frequently, followed by lopinavir/ritonavir (LPV/r) (7). Only 5 patients (18.5\%) received tocilizumab.

Most patients (35/40, 87.5\%) were given at least one antibiotic for bacterial pneumonia. Out of 14 patients given azithromycin, 6 were given concomitant CQ and another 6 received HCQ. Only 6 patients were given corticosteroid therapy (Supplementary Appendix B Table B.1).

\subsection{Intensive care unit admission}

Nine $(22.5 \%)$ patients needed admission to the intensive care unit (ICU), with 1 unable to transfer from the Emergency Department (ED) for 3 days due to bed unavailability. Of those admitted to the ICU, 5 had at least one co-morbid disease (2 CVD, 2 CVD/DM, and $1 \mathrm{CVD} / \mathrm{DM} /$ chronic lung disease). Five patients were given corticosteroids. All ICU admissions except 1 required at least 1 critical care intervention, including initiation of pressor support $(n=8)$, invasive mechanical ventilation $(\mathrm{n}=8)$, renal replacement therapy $(\mathrm{n}=6)$, and proning $(\mathrm{n}=$ 6). Median length of ICU stay was 14 (range 3-24) days. Initial sequential organ failure assessment (SOFA) score was calculable for 8 patients, with median SOFA scores increasing with length of stay: on Day 0 - median score of 3 (range 1-4); on day 3 -median score of 5.5 (range 0-11); and on day 7 - median score of 8 (range $0-14$ ).

\subsection{Outcomes}

At the time of reporting, $30(75 \%)$ patients were discharged improved; 1 (2.5\%) was discharged against medical advice; 3 (7.5\%) remain hospitalized; and $6(15 \%)$ died, all of whom had high-risk COVID-19. Mortality rate was $12.5 \%(6 / 40)$, with five deaths attributable to COVID-19. Median hospital length of stay among survivors ( $\mathrm{n}=$ 31,3 still admitted) and non-survivors $(\mathrm{n}=6)$ was 12 (range: $3-32$ days) and 14 (range: $8-24$ ) days, respectively (Table 2).

\subsection{Complications}

Twelve (30\%) patients developed at least one complication during the hospital course (Table 2). Of those with complications, 8 developed ARDS; 6 developed acute kidney injury needing renal replacement therapy; and 5 were diagnosed with septic shock and secondary bacteremia. Hospital-acquired infections including HAP/VAP developed in 5, and CRBSI occurred in 2. Eight of the 12 patients $(66.7 \%)$ who developed complications had CAP-HR while the remaining 4 had CAP-MR, of whom 3 acquired HAP, and 1 developed encephalopathy. More patients in the $>60$ age group developed complications $(8 / 21$ [38.1\%] vs. 4/19 [21.05\%]) and needed ICU level care (7/21 [34.09\%] vs. $2 / 19[10.53 \%])$.

\subsection{Clinical and virologic cure}

Clinical cure was documented in all low-risk COVID-19 patients; 24 out of 27 moderate-risk COVID-19 patients (88.9\%); and only 1 of 9 high-risk patients (11.1\%). Time to clinical cure for low to moderate risk COVID-19 took a median of 18 (5-54) days. Time to virologic cure was also shorter in the low and moderate-risk categories, taking a median of 16 (range 14-24) and 13 (range 8-27) days, respectively, compared to a median of 19.5 (range 13-26) days in the high-risk group (Table 2). 
Table 2

Complications and outcomes according to severity of COVID-19.

\begin{tabular}{|c|c|c|c|c|}
\hline OUTCOMES & $\begin{array}{l}\text { ALL CASES } \\
(\mathrm{N}=40)\end{array}$ & $\begin{array}{l}\text { Low-Risk } \\
(\mathrm{n}=4)\end{array}$ & $\begin{array}{l}\text { Moderate- } \\
\text { Risk }(\mathrm{n}=27)\end{array}$ & $\begin{array}{l}\text { High- } \\
\text { Risk } \\
(\mathrm{n}=9)\end{array}$ \\
\hline \multicolumn{5}{|l|}{ OUTCOMES, No. (\%) } \\
\hline Discharged recovered & $30(75.0)$ & $4(100)$ & $25(92.6)$ & $1(11.1)$ \\
\hline $\begin{array}{l}\text { Discharged against } \\
\text { medical advice }\end{array}$ & $1(2.5)$ & 0 & $1(3.7)$ & 0 \\
\hline $\begin{array}{l}\text { Hospitalized/Still } \\
\text { admitted }\end{array}$ & $3(7.5)$ & 0 & $1(3.7)$ & $2(22.2)$ \\
\hline Mortality & $6(15.0)$ & 0 & 0 & $6(66.7)$ \\
\hline \multicolumn{5}{|c|}{ COMPLICATIONS, No. (\%) } \\
\hline $\begin{array}{l}\text { Number of patients } \\
\text { who experienced } \\
\text { complications }\end{array}$ & $12(30.0)$ & 0 & $4(14.8)$ & $8(88.9)$ \\
\hline ARDS & $8(20.0)$ & 0 & 0 & $8(88.9)$ \\
\hline Nosocomial infection $^{a}$ & $5(12.5)$ & 0 & $3(11.1)$ & $2(22.2)$ \\
\hline Septic shock & 5 (12.5) & 0 & 0 & $5(55.6)$ \\
\hline AKI requiring RRT & $6(15.0)$ & 0 & 0 & $6(66.7)$ \\
\hline Other ${ }^{\mathrm{b}}$ : & $3(7.5)$ & 0 & $1(3.7)$ & $2(22.2)$ \\
\hline \multicolumn{5}{|l|}{ LENGTH OF STAY } \\
\hline $\begin{array}{l}\text { Hospital LOS, survivors, } \\
\text { days }\end{array}$ & $\begin{array}{l}\mathbf{n}=\mathbf{3 1} \\
12.0(7)\end{array}$ & $\begin{array}{l}\mathbf{n}=\mathbf{3} \\
9.0(12)\end{array}$ & $\begin{array}{l}\mathbf{n}=\mathbf{2 5} \\
12.0(7)\end{array}$ & $\begin{array}{l}\mathbf{n}=\mathbf{1} \\
14 \text { days }\end{array}$ \\
\hline $\begin{array}{l}\text { Median (IQR) } \\
\text { min-max }\end{array}$ & $3-32$ & $4-16$ & $3-32$ & \\
\hline $\begin{array}{l}\text { Hospital LOS, non- } \\
\text { survivors, days }\end{array}$ & $\begin{array}{l}\mathbf{n}=\mathbf{6} \\
14.0(11)\end{array}$ & $\begin{array}{l}\mathbf{n}=\mathbf{0} \\
-\end{array}$ & $\begin{array}{l}\mathbf{n}=\mathbf{0} \\
-\end{array}$ & $\begin{array}{l}\mathbf{n}=\mathbf{6} \\
14.0(11)\end{array}$ \\
\hline $\begin{array}{l}\text { Median (IQR) } \\
\text { min-max }\end{array}$ & $8-24$ & & & $8-24$ \\
\hline ICU stay, No. (\%) & $9(22.5)$ & 0 & $1(3.7)$ & $8(88.9)$ \\
\hline $\begin{array}{l}\text { Duration of ICU stay, } \\
\text { days }\end{array}$ & $\begin{array}{l}\mathbf{n}=\mathbf{9} \\
14.0(11)\end{array}$ & $\begin{array}{l}\mathbf{n}=\mathbf{0} \\
-\end{array}$ & $\begin{array}{l}\mathbf{n}=\mathbf{1} \\
1 \text { day }\end{array}$ & $\begin{array}{l}\mathbf{n}=\mathbf{8} \\
15.0\end{array}$ \\
\hline $\begin{array}{l}\text { Median (IQR) } \\
\text { min-max }\end{array}$ & $3-24$ & & & $\begin{array}{l}(10.5) \\
8-24\end{array}$ \\
\hline \multicolumn{5}{|l|}{ Clinical cure, No. (\%) } \\
\hline Yes & $30(75.0)$ & $4(100)$ & $25(92.6)$ & $1(11.1)$ \\
\hline No & $10(25.0)$ & 0 & $2(7.7)$ & $8(88.9)$ \\
\hline \multicolumn{5}{|l|}{ Virologic cure, No. (\%) } \\
\hline Yes & $25(62.5)$ & $4(100)$ & $19(70.4)$ & $2(22.2)$ \\
\hline No & $6(15.0)$ & 0 & $5(18.5)$ & $1(11.1)$ \\
\hline Unknown & $9(22.5)$ & 0 & $3(11.1)$ & $6(66.7)$ \\
\hline $\begin{array}{l}\text { Time to virologic cure, } \\
\text { days }\end{array}$ & $\begin{array}{l}\mathbf{n}=\mathbf{2 5} \\
13.0(4)\end{array}$ & $\begin{array}{l}\mathbf{n}=4 \\
16.0(5)\end{array}$ & $\begin{array}{l}\mathbf{n}=19 \\
13.0(6)\end{array}$ & $\begin{array}{l}\mathbf{n}=\mathbf{2} \\
19.5(13)\end{array}$ \\
\hline $\begin{array}{l}\text { Median (IQR) } \\
\text { min-max }\end{array}$ & $8-27$ & $14-24$ & $8-27$ & $13-26$ \\
\hline Mortality, No. (\%) & $6(15.0)$ & - & - & $6(66.7)$ \\
\hline COVID-related & 5 (12.5) & - & - & $5(55.6)$ \\
\hline Not COVID-related & $1(2.5)$ & - & - & $1(11.1)$ \\
\hline
\end{tabular}

AKI - acute kidney injury, ARDS - Acute Respiratory Distress Syndrome, CRBSI Catheter Related Bloodstream Infection HAP -Hospital Acquired Pneumonia, IQR -interquartile range, LOS - length of stay, RRT - renal replacement therapy VAP - Ventilator Associated Pneumonia.

a VAP (3), HAP (2), CRBSI (2).

b Encephalopathy (1), pneumomediastinum (1), pneumothorax (1).

Among survivors, median length of hospital stay between the two different age groups was similar [12 (range 4-30) days vs. 11 (range 3-32) days]. The younger age group had a higher frequency of clinical (17/19 [89.5\%] vs. 13/21 [61.9\%]) and virologic cures (15/19 [78.9\%] vs. $10 / 21[47.5 \%])$, and a lower mortality rate $(2 / 19$ [10.5\%] vs. $4 / 21$ [19\%]) compared to the older age group (Supplementary Appendix B Table B.2).

\section{The TMC healthcare systems response}

As a Joint Commission International-accredited hospital, TMC has established systems in place for health disasters and emerging and reemerging diseases such as SARS in 2003, leptospirosis in 2009, and dengue in 2018. The surge of COVID-19 cases in the TMC ED and the critical care units posed a unique healthcare challenge like no other. In response, TMC made initial preparations by convening its Epidemic Rapid Response Team on January 20, 2020, subsequently meeting weekly to prepare the hospital for the surge of COVID-19 patients.

After confirmation of the first case in TMC and a rapidly growing number of cases, several changes were made to the hospital system. A one-way hospital traffic system was created by sealing several entry ways and designating a single point of entry and exit. A screening area in the ED was set up, and separated into COVID-19 and non-COVID areas, with the appropriate engineering controls and uni-directional flow of traffic. A supplemental triage area was built near the ambulatory area in order to effectively direct febrile patients to the ED, instead of the outpatient clinics. Several units, including the acute stroke unit, and two general medical floors were designated as dedicated units for probable and confirmed COVID-19 cases, with each unit having assigned donning and doffing areas, and one-way traffic. Finally, a clinical pathway with clear case definitions was created in order to easily capture COVID-19 patients and integrate rapidly evolving evidence on clinical management (Fig. 1). Enhanced infection prevention and control measures, including intensive training of HCWs on donning and doffing of full personal protective equipment (PPE), and patient and staff cohorting were also implemented. HCWs with advanced age and co-morbid disease were also assigned to non-COVID-19 areas.

\section{Discussion}

We describe the first 40 confirmed COVID-19 cases admitted in our institution and highlight several clinical findings and observations regarding our health systems response to surge capacity. TMC admitted patients during the early course of the COVID-19 epidemic. Our first few cases were from a family cluster and portrayed person-to-person transmission among close contacts. The study by Chan et al. ${ }^{13}$ documented familial transmission by showing that genome sequences from two different family members showed almost identical nucleotides with each other. In our cluster, although we were unable to perform genomic analysis, the index patient and his wife stayed with a family of five - and only the three who spent more time with the index patient were confirmed to have COVID-19 infection. (Supplementary Appendix A Fig. A.1). This validates existing data that transmission risk is more likely with recurrent, close contact. ${ }^{13}$ That the index case and the rest of his family sought consult late also suggests that the index of suspicion for COVID-19 was low despite informational campaigns, the presence of travel history, and compatible symptoms. At this time, many were likely unaware of community transmission, and there remained a need to significantly raise the awareness of people about the signs and symptoms of COVID-19.

The median time from symptom onset to admission was 7 days (range 0-42 days) in our cohort, mirroring the findings in other studies. ${ }^{3,4}$ However, 19 patients first presented a median of 4 days after symptom onset but were not hospitalized. This suggests that persistence or progression of symptoms was necessary before patients were considered for hospital admission. This was consistent with the Philippines' Department of Health directives, which mandated prioritization of older and sicker patients. However, 4 of 19 patients who were seen in the ambulatory setting died from COVID-19; this potential delay in admission may have contributed to poor outcomes in these patients.

From a clinical perspective, we confirm the findings of a recent metaanalysis ${ }^{14}$ that fever, cough and weakness are the most frequent symptoms, and that severe disease is more common in the older age group and those with co-morbidities. ${ }^{3,4}$ Our rates of complication, severe illness, and ICU admission are also comparable to other case series. ${ }^{3,4,15}$

Majority of patients, including all patients in the high-risk group, were given at least one drug repurposed for the treatment of COVID-19 infection, despite the lack of robust evidence to support their use. Several clinical guidelines ${ }^{9,16}$ cautioned against the routine use of these drugs outside of clinical trials, since the benefits from these drugs were unproven. Recent evidence from the Solidarity and Recovery randomized clinical trials ${ }^{17,18}$ show that the use of HCQ, CQ and LPV/r were indeed unwarranted, and these are no longer recommended. Despite the 


\section{Confirmed cases $\longrightarrow$ Probable cases}

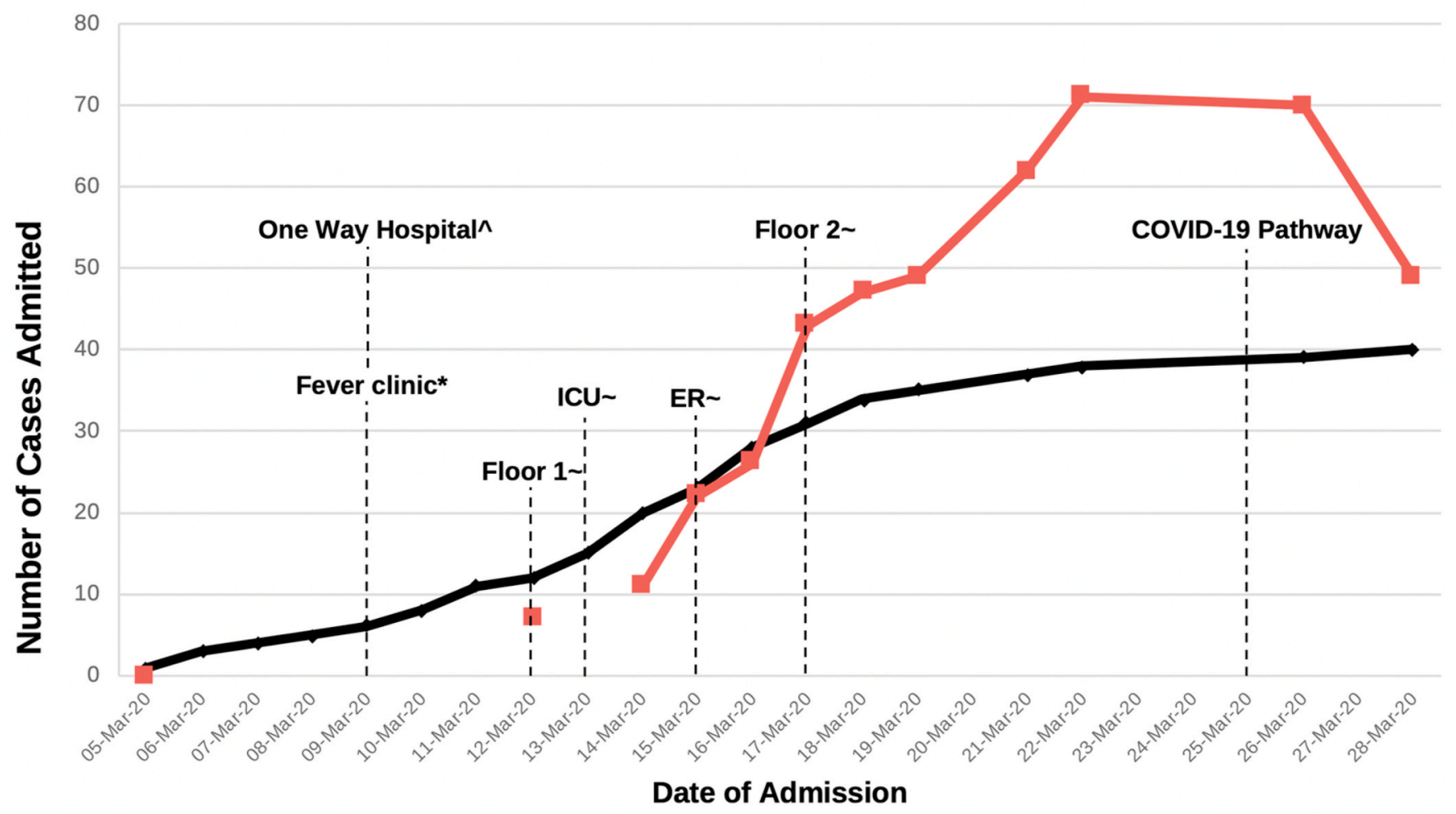

Fig. 1. Legend: Graph showing probable and confirmed COVID-19 cases and hospital response.

Footnote:

Number of probable COVID-19 cases from March 6-11 and March 13 not captured.

^ Only one entrance-exit and uni-directional flow allowed.

* Triage clinic for patients entering the ambulatory area.

$\sim$ Units $\mathrm{w}$ /negative pressure rooms or rooms with hepa filters assigned for probable or confirmed COVID-19 patients only.

poor quality of evidence, ${ }^{16,19}$ however, physicians are often compelled to start these drugs because of many reasons- the severity of illness, external pressure from other physicians or patients' family and relatives, and social media. Moving forward, the urge to use unproven treatments based on anecdotal success and outside of well-designed randomized clinical trials needs to be resisted, especially in light of doing possible harm.

Time to virologic cure took several days, and was longer with greater disease severity and older age. Current guidelines ${ }^{9,20}$ report the need to document 2 negative RT-PCR results before patients are declared "virologically cured." In our study, we chose at least 1 negative test result since the subsequent test is usually performed elsewhere and we are unable to capture that data. Studies ${ }^{21,22}$ have shown that although viral shedding can last several weeks, this virus could be non-viable by day $8^{22}$. The test-based strategy - having to repeat RT-PCR until twice negative has been revised and a "non-testing-based strategy" considered instead. Except for high-risk and severely ill patients, discontinuing isolation along with universal source control and standard precautions may be more cost-effective than recurrent testing, especially in resource-poor settings.

The abrupt increase in both probable and confirmed COVID-19 cases during the first month highlighted the need for the hospital to adapt quickly to the surge. Surge capacity, often defined as the ability of a healthcare system to respond to a sudden increase in patient care demands, conceptually contains the following components: supplies, personnel, physical space, and management infrastructure, sometimes referenced as "stuff, staff, and structure". ${ }^{23,24}$

In our study, "stuff" in the form of testing capacity took too long, with confirmation of SARS-CoV-2 infection by RT-PCR taking a median of 5 days. In the US and China, turn-around time is usually within a few hours of testing. ${ }^{3,15}$ The long delay was primarily because the test was sent out and performed at a reference laboratory. This prolonged turn-around time (TAT) had several healthcare and infection control implications, including the inability to effectively triage non-COVID-19 patients outside of airborne isolation precautions and ration the use of PPE. The long wait also caused increased anxiety for HCWs, the patients, and their family members. At the time of this report, testing is now done at TMC, and TAT is much shorter at 2 days. Nationally, from one reference laboratory performing RT-PCR at the start of the COVID-19 outbreak in the country, the number of licensed RT-PCR laboratories has grown to 108, supplemented by 34 licensed cartridge-based PCR or GeneXpert laboratories (as of October 9, 2020, https://www.doh.gov. $\mathrm{ph} /$ covid19tracker).

Our staff were also reshuffled and assigned to patients in COVID-19 units to limit cross-contamination. This method of patient and staff cohorting is often used to curtail outbreaks of multi-drug resistant organisms $^{25,26}$ and emerging infections. ${ }^{26}$ However, isolation and cohorting are difficult to sustain because of higher cost and increased workload for the healthcare team. ${ }^{27,28}$ In addition, adverse events such as increased patient anxiety, anger or feeling of isolation, increased falls, and less time spent with the healthcare team, have been reported ${ }^{29}$ events that we also observed for some of our patients.

Adequate physical space and appropriate structures are often underestimated needs in surge capacity. ${ }^{23}$ However, our hospital space was rapidly re-organized to accommodate the rise in COVID-19 cases several units were dedicated for probable and confirmed COVID-19 
cases, with each unit having assigned donning and doffing areas and one-way traffic. These adaptations made it easier for the staff to safely and adequately manage these patients.

Our study has some limitations inherent to a retrospective study reporting on the first 40 patients in our institution. We used categories of COVID-19 severity based on national guidelines, but which are comparable to international definitions. Despite these limitations, our study is the first to describe COVID-19 patients hospitalized in a private tertiary-level hospital in the Philippines. Our experience may not necessarily represent the patient profile and health care system in the Philippines' public sector, but illustrates the challenges that even wellresourced health facilities in developing countries face.

We validate findings from studies in Wuhan, China during the early days of the pandemic that both older age and presence of a co-morbid disease are associated with more severe disease and poor outcome. ${ }^{2-4}$ We identified specific issues that affected initial response to surge capacity, including the prolonged TAT for disease confirmation, the need to re-organize the hospital space and staff, and the need to increase level of awareness of ongoing COVID-19 community transmission. Finally, our report highlights the need for rapid adaptive actions by the healthcare system to respond to the surge of COVID-19 cases and for long-term, innovative strategies for continuing essential hospital services in the new health context created by the COVID-19 pandemic.

\section{Funding}

This research did not receive any specific grant from funding agencies in the public, commercial, or not-for-profit sectors.

\section{Conflicts of interest}

The authors declare that there is no conflict of interest.

\section{Author contributions}

All authors contributed to study design; CLA, CPC, MAL - contributed to data analysis, manuscript writing; CLA/JB/JF/EV/MFT/BT/ $\mathrm{MBB}$ - data collection and management; MCS/NPB/EPP/BT/KH - protocol feedback, manuscript writing.

\section{Acknowledgments}

We would like to acknowledge Kathy Rayos, clinical pharmacist, for her help with the manuscript.

\section{Appendix A. Supplementary data}

Supplementary data to this article can be found online at https://doi. org/10.1016/j.cegh.2020.100695.

\section{References}

1 Zhu N, Zhang D, Wang W, et al. A novel coronavirus from patients with pneumonia in China. The New England journal of medicine. 2020. 2019;382:727-733.

2 Chen N, Zhou M, Dong X, et al. Epidemiological and clinical characteristics of 99 cases of 2019 novel coronavirus pneumonia in Wuhan, China: a descriptive study. Lancet (London, England). 2020;395:507-513.

3 Huang C, Wang Y, Li X, et al. Clinical features of patients infected with 2019 novel coronavirus in Wuhan, China. Lancet (London, England). 2020;395:497-506.
4 Wang D, Hu B, Hu C, et al. Clinical characteristics of 138 hospitalized patients with 2019 novel coronavirus-infected pneumonia in Wuhan, China. Jama. 2020;323(11): 1061-1069. https://doi.org/10.1001/jama.2020.1585.

5 Edrada EM, Lopez EB, Villarama JB, et al. First COVID-19 infections in the Philippines: a case report. Trop Med Health. 2020;48:21.

6 Department of Health Philippines. COVID-19 tracker: Philippines. https://ncovt racker.doh.gov.ph/. Accessed May 2, 2020.

7 World Health Organization. Clinical management of severe acute respiratory infection when novel coronavirus (COVID) infection is suspected. Interim guidance. 28 January 2020.

8 https://www.who.int/emergencies/diseases/novel-coronavirus-2019/situation-repo rts/.

9 Philippine Society for Microbiology and Infectious Diseases. Interim guideline on the clinical management of adult patients with suspected or confirmed COVID-19 infection. 28 March 2020. Version 2.0.

10 Horan TC, Andrus M, Dudeck MA. CDC/NHSN surveillance definition of health careassociated infection and criteria for specific types of infections in the acute care setting. Am J Infect Contr. 2008;36:309-332.

11 Ranieri VM, Rubenfeld GD, Thompson BT, et al. Acute respiratory distress syndrome: the Berlin Definition. Jama. 2012;307:2526-2533.

12 Asia Pacific Biotech news. http://www.worldscientific.com. Accessed April 15, 2020. p. 26.

13 Chan JF, Yuan S, Kok KH, et al. A familial cluster of pneumonia associated with the 2019 novel coronavirus indicating person-to-person transmission: a study of a family cluster. Lancet (London, England). 2020;395:514-523.

14 Sun P, Qie S, Liu Z, Ren J, Li K, Xi J. Clinical characteristics of hospitalized patients with SARS-CoV-2 infection: A single arm meta-analysis. J Med Virol. 2020;92(6): 612-617. https://doi.org/10.1002/jmv.25735. Epub 2020 Mar 11.

15 Richardson S, Hirsch JS, Narasimhan M, et al. Presenting characteristics, Comorbidities, and outcomes among 5700 patients hospitalized with COVID-19 in the New York City area. Jama. 2020;323(20):2052-2059. https://doi.org/10.1001/ jama.2020.6775.

16 Bhimraj A, Morgan RL, Shumaker AH, et al. Infectious Diseases Society of America Guidelines on the Treatment and Management of Patients with COVID-19. Clinical Infectious Diseases. an official publication of the Infectious Diseases Society of America; 2020.

17 Horby P, Mafham M, Linsell L, et al. Effect of Hydroxychloroquine in Hospitalized Patients with COVID-19: Preliminary results from a multi-centre, randomized, controlled trial. https://www.medrxiv. org/content/10.1101/2020.07.15.20151852v1. 2020.

18 Pan H, Peto R, Karim Q, et al. Repurposed antiviral drugs for COVID-19-interim WHO SOLIDARITY trial results. https://www.medrxiv. org/content/10.1101/2020.10.15.20209817v1.full.pdf. 2020.

19 Siedner MJ, Gandhi RT, Kim AY. Desperate times call for temperate measures: practicing infectious diseases during a novel pandemic. J Infect Dis. 2020;222(7): 1084-1085. https://doi.org/10.1093/infdis/jiaa209.

20 Criteria for return to Work for healthcare personnel with suspected or confirmed COVID-19 (interim guidance). https://www.cdc.gov/coronavirus/2019-ncov/hcp/ return-to-work.html; 2020.

21 Wolfel R, Corman VM, Guggemos W, et al. Virological Assessment of Hospitalized Patients with COVID-2019. Nature. 2020;581(7809):465-469. https://doi.org/ 10.1038/s41586-020-2196-X.

22 Xiao AT, Tong YX, Zhang S. Profile of RT-PCR for SARS-CoV-2: A Preliminary Study from 56 COVID-19 Patients. Clinical Infectious Diseases. an official publication of the Infectious Diseases Society of America; 2020.

23 Hick JL, Koenig KL, Barbisch D, Bey TA. Surge capacity concepts for health care facilities: the CO-S-TR model for initial incident assessment. Disaster medicine and public health preparedness. 2008;2(Suppl 1):S51-S57.

24 Kaji A, Koenig KL, Bey T. Surge capacity for healthcare systems: a conceptual framework. Acad Emerg Med : official journal of the Society for Academic Emergency Medicine. 2006;13:1157-1159.

25 Abad CL, Barker AK, Safdar N. A systematic review of the effectiveness of cohorting to reduce transmission of healthcare-associated C. difficile and multidrug-resistant organisms. Infect Contr Hosp Epidemiol. 2020:1-19.

26 Tan YM, Chow PK, Tan BH, et al. Management of inpatients exposed to an outbreak of severe acute respiratory syndrome (SARS). J Hosp Infect. 2004;58:210-215.

27 Lucet JC, Armand-Lefevre L, Laurichesse JJ, et al. Rapid control of an outbreak of vancomycin-resistant enterococci in a French university hospital. J Hosp Infect. 2007; $67: 42-48$.

28 Reeme AE, Bowler SL, Buchan BW, et al. Use of a cohorting-unit and systematic surveillance cultures to control a Klebsiella pneumoniae carbapenemase (KPC)producing Enterobacteriaceae outbreak. Infect Contr Hosp Epidemiol. 2019;40: $767-773$.

29 Abad C, Fearday A, Safdar N. Adverse effects of isolation in hospitalised patients: a systematic review. J Hosp Infect. 2010;76:97-102. 